\title{
From dealing with teacher resistance to working on teacher resilience ${ }^{1}$
}

\section{De lidiar con la resistencia de los profesores a trabajar en la resiliencia de los profesores}

\author{
Hayo Reinders ${ }^{2}$ \\ Unitec - New Zealand \\ www.innovationinteaching.org
}

How to cite this article (APA, 6th ed.): Reinders, H. (2018). From dealing with teacher resistance to working on teacher resilience. Enletawa Journal, 11 (1), 69-76

\section{From dealing with teacher resistance to working on teacher resilience}

In a time of constant change and disruption in education, it is common for teachers to feel anxious about their chosen career. Teacher 'resistance' is a natural response in such circumstances and one that can take a significant personal and professional toll, both on the individual and those in their community. In this article I aim to take a more positive approach and frame teachers' responses to change as a form of resilience, rather than resistance, and as a mindset that can be harnessed for the benefit of the individual as well as the organisation. Besides, I offer some recommendations for managers on developing a positive mindset and for teachers to take on a leadership role within the institution.

1 This article was originally published at Modern English Teacher in 2017. The original publication details are:

Reinders, H. (2017). A positive approach to dealing with teacher resistance. Modern English Teacher, 26(3), 20-22 and

Reinders, H. (2017). Moving from teacher resistance teacher-leadership. Modern English Teacher, 26(2), 74-76.

Enletawa Journal has gotten expressed permission to republish it.

2 Hayo Reinders is Professor of Education at Unitec in New Zealand and TESOL professor and director of the doctoral programme at Anaheim University in the USA. He has published over 20 books and 100 articles in areas of autonomy, technology, teacher education and out-of-class learning. He edits a book series for Palgrave Macmillan and is editor of the journal Innovation in Language Learning and Teaching. 
A new term, a new manager, a new 'grand plan'. It's only a few weeks before the start of semester and the new head has decided all classes will be given tablets and teachers will be required to use these to 'flip' their instruction. During several 'planning' meetings, some voice concerns, but these are quickly dismissed in favour of the need to 'move with the times'. After this, staff mostly keep their doubts to themselves. 'I have never used tablets before in my teaching, I wouldn't know where to begin,' thinks Amon. 'My students are young and inexperienced. What if they don't complete the "flipped" work between classes. How am I going to support them?' worries Kesha. 'Why don't we spend the money on hiring more teachers instead,' thinks Li.

Fast-forward six months. Most of the classes have stopped using the tablets and the devices are sitting idly on the shelves. Significant expense has been made which has led to a reduction in the budget for staff salaries. Salary raises for next year are out of the question and there is even talk of downsizing. School management has asked for a report from an external consultant, explaining the cause of the failure of the project. This is found quickly: teachers are resistant to change and unwilling to change their practices. The consultant recommends compulsory professional development for all teachers on 'teaching 21st century skills', to begin immediately. The new manager has resigned.

\section{A more positive perspective on teacher resistance}

Although the example above is made up, it is a common scenario in many workplaces everywhere.
Successes are attributed to 'visionary' leaders, and failures to passive teachers who are resistant to new ideas.

However, as the example above makes clear, in most cases teachers have genuine and reasonable concerns about protecting their own professional practice as well as their learners. A more positive approach is to see scenarios such as the above as reflecting hesitation and caution, rather than an outright rejection of change, and to view teachers as resilient, rather than resistant. As Miller and Rollnick (2002) point out:

To use the term "resistance" as explanatory seems to suggest that things are not going smoothly because of something that one person [...] is doing. ... In a way, it is oxymoronic to say that one person is not cooperating. It requires at least two people to not cooperate, to yield dissonance. (p. 45)

This opens the door to viewing challenges in the workplace as opportunities to explore. If we assume that teachers act with good intentions and that the success or failure of new initiatives is the responsibility of both teachers and those around them, we can start to look at ways in which relationships can be built that are more sustainable in the long term. Rather than 'managing' resistance, we move towards constructive leadership that values and actively draws on teachers' resilience in the face of change and look at the roles that both managers and teachers take in this process. 
Why teachers struggle

With increased workloads, more frequent and more disruptive changes, educators are experiencing more stress than ever before. It is important to look at the ways in which this stress manifests itself differently in people.

At a personal level, people vary greatly in the way they respond to pressure and changes in their environment. People with different personality types react differently, as do people with more or less experience in the workplace, or those with prior management experience and those without. There is a significant amount of information in the management literature on the different predispositions, attitudes and beliefs that people have and how these inform how they act in the workplace. Toropov (1997), in his whimsically titled book Manager's Guide to Dealing with Difficult People, talks about different frames of reference that inform how people view their reality. For example, some people prioritise doing things by themselves, whereas others prefer to do things through other people. Similarly some people prefer to get things out of the way, whereas others prefer to do things error-free. Together, these form a quadrant with the 'Lone Ranger' in the top left-hand corner, the 'Cheerleader' in the top right-hand corner, the 'Sharpshooter' in the bottom-left corner, and the 'Professor' in the bottom-right corner. Although such categorisations are useful to understand different people's actions, it is important to remember that we all take on different roles at different times. The point here is to challenge ourselves to ask what perspective any one person is taking at any one time, and to realise that this perspective may be different from our own. This will then allow us to adjust the way that we communicate with that person. The management literature contains a lot of resources that can help with this.

One thing that causes anxiety for many people is uncertainty. Not knowing what is going to happen is cited by many teachers (and numerous research studies) as a reason for feeling a lack of control and discomfort. Most people appreciate predictability in their professional lives and structure in their everyday work. When these are threatened, people can react emotionally. A common response is to question one's ability to respond to upcoming changes and to meet the challenges of the new environment, or even one's professional capability more broadly. Questions such as Will I be successful in teaching online?, Will I be able to work well in a teambased approach?, or How can I possibly motivate these new students we are taking on? can reflect deep levels of concern. Understanding these feelings can help to better anticipate possible reactions to new initiatives. It can also help to change the way in which a message about upcoming changes is phrased. For example, rather than merely emphasising what will be different, it is possible to highlight how the changes build on existing structures, methods of teaching, resources, and so on.

Another major influence on the level of anxiety that people experience in the face of change is the nature of the change itself. The larger the gap between the current situation and the 
proposed, the more commonly people respond hesitantly. If the changes are seen to be minor, transitional or incremental, they are more likely to be accepted (Stoller, 1994). This is one reason why a number of well-planned and sequenced changes are more likely to be successful than one large one.

Similarly, changes that are perceived to carry benefits are more likely to be welcomed. It is important to distinguish between individual and organizational benefits. Whereas reducing the cost of teaching may be beneficial to the organization, this may have no benefit, and even be a detriment to individual staff. However, often it is possible to identify a link between the two. For example, if teaching costs are reduced, this may mean there is more money available for teachers' professional development.

Perhaps the most important variable is the degree of agency that teachers feel they have over their environment. As highly reflective professionals, teachers place great value on understanding why things are done the way they are (Fullan, 2007). Many unsuccessful projects do not involve sufficient background information, a clear rationale and poor consultation.

Understanding what motivates people is an important first step in any successful manager's repertoire. Teachers do not respond 'negatively' just because they are unwilling to change or take on new ideas. Teachers, as reflective professionals, do have reasonable concerns. It is the manager's responsibility to consider these concerns and the most appropriate ways to address them.

Of course, this responsibility goes both ways; teachers themselves also need to take on a proactive role in making the institution successful and in supporting learners' success.

As we have previously discussed, many teachers are experiencing increased stress and anxiety in the workplace. We looked at a range of reasons for why teachers sometimes struggle, in particular in the face of change and disruption. We also looked at ways of understanding how such responses could be looked at more positively than by simply labelling them as resistance. Now, we look at ways in which teachers can be empowered to make a positive and sustainable contribution and to take on leadership roles.

A leadership approach to teaching considers the reasons for perceived resistance, and tries to understand the positive motivations that may lead to what superficially may seem to be a reluctance to participate, or to adopt change. It attempts to conceptualize resilience as a positive force that can be harnessed to make an institution successful. Such an approach also considers the potential impact of changes, as long as possible before they take place. This requires careful planning. Changes that occur proactively, rather than reactively, and that are well considered are more likely to be successful.

Part of this planning involves considering how people's backgrounds, 
beliefs, attitudes and personalities may affect how they feel about themselves as teachers, the institution as a whole, their community of practice, as well as you as their manager. This will also help you to anticipate how people may respond differently in the face of change. You will need to consider how different members of your team may appreciate, or even require different types of communication. Some may prefer a personal message in the form of an informal conversation, whereas others will benefit from background reading and sufficient time to understand the issues at hand. The amount of time and care you dedicate to this part of the process will determine how your team perceives your intentions. Discussing a significant development as the last agenda item at a regular staff meeting, given only 10 minutes, may signal to staff that their input is not actually needed. Similarly, if there is no opportunity to speak up freely, and for genuine discussion to take place, staff quickly recognize the project as a top-down imposition, rather than a collaborative exercise. Consider your objectives for engaging with staff. Do you want their consent, their approval, their enthusiasm, or do you simply want to inform them?

Good communication helps minimize uncertainty. Although the nature of change is such that often it is not possible to predict exactly what will happen and when, do keep people up-to-date as early and as frequently as possible. If you are aware that new guidelines are coming out from the ministry of education, highlight this in meetings so that staff are aware that there may be an impact on their practice. When the actual report is then published, disseminate it to your staff as quickly as possible, perhaps highlighting key areas of direct import to the team. The need to communicate frequently continues throughout a project. Consider how all stakeholders can best be kept informed, and can be given an opportunity to have their say, without fear of reprisal.

Uncertainty can also be minimized by good planning. A clear schedule of what is expected to happen, what will be involved at what stage, and by what point different milestones are to be achieved, makes it clear to everyone involved what to expect. By sharing this early, you may receive valuable feedback on what may or may not be realistic timelines and you reduce uncertainty.

Staff uncertainty often relates to a lack of confidence and professional skills, such as in the area of integrating technology in the classroom. Look for opportunities for the project to help staff acquire new skills in a safe environment. This type of professional development is often carried out intensively, over a very short period of time, at the start of a project. More successful change implementations continue staff support and development throughout the entire process.

Although your tendency may be to be very enthusiastic about an upcoming project, do not forget your audience.

Not everyone may immediately 'jump on the bandwagon' and people may need time to digest and understand new ideas. Clearly lay out the objectives 
of a project and the reasons why these are important. Then, identify evidence to support the link between the project, its objectives and its intended benefits, and share as much of this as possible with the staff. This could be in the form of research reports, scientific publications, case studies from other institutions, conference presentations, and so on.

Finally, and perhaps most importantly, consider the ways in which you can increase teachers' sense of agency. Rather than seeing teachers as an obstacle to your project, consider how you can harness the significant collective experience, passion and overriding interest in student learning outcomes to achieve your team's long-term goals. In this sense, teachers can help to identify potential problems with the project at an early stage (Farrell, 2014). Ways in which to engage teachers include using workshops, or creating small 'think tanks' or 'taskforces', online communities and a variety of other formats, to help gather information to better understand the challenges the institution is facing, and to look for experiences from elsewhere that can be used to draw meaningful implications for your own context.

An often-used technique is to identify different areas or topics that relate to a broader project. For example, when considering implementing a learning management system, one group of teachers could look at its use in the classroom, another at ways in which the system can be used to support learning beyond the classroom, a third group could look at ways in which the system may be used to automate some aspects of the assessment practices in the school, with a final group looking at professional development needs. If teachers are not in a position to spend a great deal of time, as a manager you may be able to create a number of scenarios, based on existing research and literature, for the team to respond to. The aim is to make a genuine effort to involve teachers, and to instil a sense of ownership of a project.

Related to the above, consider the use of pilot studies, where a small group of teachers carries out part of a project in a safe environment. These teachers can then report back their experiences to the rest of the team, so that changes are not seen to be emanating directly and solely from you.

A final point is to ensure there is sufficient time for a change project. Many projects fail because they simply do not account for the investment in time needed to make the change part of a collaborative process, and simply look at the technical aspects of the project. Change projects are time-consuming and expensive. However, even more expensive are those projects that are not successful.

Of course, leadership does not rest solely with managers, but is a shared responsibility (Hargreaves and Fink, 2005). In any case, most managers have a manager themselves and knowing how to respond in stressful situations is a key skill for all teachers, regardless of their level of institutional seniority.

\section{The manager's perspective}

Let us now consider how the opening scenario of the previous 
pages of this article was experienced by the manager in question in that scenario. I described how a new manager attempted to introduce the implementation of tablets into a school, with disastrous results:

Monday morning, the first staff meeting to plan for the new year. After many months of hard work, finally approval has been given and funding has been made available for an exciting new initiative in the school. Tablets will be made available to all students, giving teachers a wonderful opportunity to make their lessons more interactive, and also assuring that all children will have access to technology in the home (something that was previously not the case). Unfortunately, things do not get off to a good start. Even before he begins to talk there are of the many dreaded long faces around the table. Not a hint of enthusiasm at his announcement of the news, and not a single thank you for his efforts in securing new resources. In the follow-up meetings things continue in this way. Rather than looking at the development as an opportunity, everyone seems to have something to complain about. When will they ever be happy?

Clearly, a very different perspective is evident here than that experienced by the teachers, at the beginning of this article. The aim here is not to identify which is right or wrong, but to establish that two groups of people, both usually with very good intentions, can have very different views; with often disastrous results. Let me now consider how individual teachers can take on a leadership role in a context of change.

\section{Teacher-leadership}

Some teachers have been managers themselves in previous roles. Many will one day have to take on managerial roles, either as course leaders, programme directors, or heads of school. Regardless of your current position, consider what role you can take on to support your manager, your colleagues and your institution. Looking back at the two scenarios at the start of this article and at the start of the preceding section, what differences can you identify? And in what ways could you help to bridge these differences?

Looking back over the list of causes of anxiety, as well as the suggested remedies, what roles could you play to help match the two? For example, if you generally enjoy change, how might you support a colleague who prefers the status quo? If you have some previous experience, say in using a particular language test or a particular teaching method, perhaps put your hand up to help your colleagues.

If at a staff meeting you sense your colleagues' concerns, for example because information is not presented clearly, take it upon yourself to ask constructive, non-threatening questions. If the benefits of the proposed project are not clear, offer to do some research on other schools' experiences and published studies. If you feel that you and your colleagues are not being given the agency to meaningfully contribute to the project, it may be diplomatic to have a quiet word with your manager after the meeting. Offer some suggestions on how you and your colleagues might be able to be 
involved. In other words, do not simply raise concerns but also offer practical suggestions.

Finally, realize that your manager probably has good intentions and may not have much experience in this type of situation. Remember that both of you, as well as all of your colleagues, are part of the same team, and that your ability to collaborate successfully will determine the effect of the project on your students.

\section{Conclusion}

Successful teams are those that work together and this collaboration is the responsibility of all involved. Understanding how people respond to pressures at work and to changes in particular is a good starting point to consider how best to communicate, collaborate and draw on the collective energy and experience in your team. And understanding how different people can have vastly different perspectives on a given situation helps us to remember to take care in how we judge and choose to work with others. Although not all aspects of leadership can be shared, the approach outlined here does recognize that leadership is a shared responsibility. By taking on this shared task, your students will, in the long-term, benefit.

\section{References}

Farrell, T. (2014). Promoting Teacher Reflection in Second Language Education: A Framework for TESOL Professionals. New York: Routledge.

Fullan, M. (2007). Leading in a culture of change. San Francisco: JosseyBass.

Hargreaves, A., and Fink, D. (2005). Sustainable Leadership. San Francisco: Jossey-Bass.

Miller, W., and Rollnick, S. (2002). Motivational Interviewing: Preparing People for Change. New York: Guilford Press.

Stoller, F. (1994). The diffusion of innovations in ESL programs. Applied Linguistics, 15 (3), 300327.

Toropov, B. (1997). Manager's Guide to Dealing with Difficult People. Paramus, NJ: Prentice Hall. 